\title{
Use of Measurement Uncertainty in Compliance Assessment in Custody Transfer Operations
}

\begin{abstract}
Oliveira EC*
Postgraduate Programme in Metrology, Pontifical Catholic University of Rio de Janeiro \& Petrobras Transporte S.A. - TRANSPETRO, Brazil
\end{abstract}

*Corresponding author: Elcio Cruz de Oliveira, Pontifical Catholic University of Rio de Janeiro, Brazil, Email: elciooliveira@puc-rio.br

\section{Editorial \\ Volume 5 Issue 4}

Received Date: October 02, 2021

Published Date: October 12, 2021

DOI: $10.23880 /$ ppej- 16000278

\section{Editorial}

Starting from production until reaching the final consumer, at each stage, the oil and its derivatives can be can carried under the responsibility of a different company that, sequentially, transfers it to the next company, by means of processes called custody transfers. These measurement results, due to the large financial amounts involved in the oil and gas industry, must be reliable, considering that compliance must be assessed between suppliers and customers in custody transfer operations, avoiding unnecessary conflicts in these commercial relationships. This is why the results must be statistically compatible.

The compatibility between results and the decisionmaking concerning this process can be made based on the measurement uncertainty and guard band concept [1]. This new powerful approach that has been used to evaluate the conformity against regulatory limits $[2,3]$, also, can be used successfully to assess the compliance between two parties involved in custody transfer operations, client and supplier. A great challenge is to balance cost versus quality (measurement uncertainty). As the value of this quality parameter is minimized, more investments are required in better measurement conditions, that is, significant costs.

Based on the International Organization of Legal Metrology [4], the accuracy class of type of measuring system takes into consideration the field of application. Thus measuring systems on pipelines must have a maximum measurement uncertainty of $0.3 \%$, during custody transfer operations. On the other hand, the static measurement in storage tanks depends on the level of product transferred, the tank capacity tables, the density of the fluid and the temperature during the transfer custody operations, etc... Therefore, there is no single fixed uncertainty [5].
Let us suppose two different scenarios of custody transfer operations of diesel.

The first one, the supplier measured $100.1 \mathrm{~m}^{3} \pm 0.3 \mathrm{~m}^{3}(\mathrm{k}$ $=2$; confidence level of 95.45) and the consumer measured $100.0 \mathrm{~m}^{3} \pm 0.3 \mathrm{~m}^{3}(\mathrm{k}=2$; confidence level of 95.45), both using a turbine fiscal oil metering station (Figure 1). Considering a risk of $5 \%$ for the consumer, is there compliance between the parties?



This item is not confirm to an effective Consumer's Risk of $5 \%$. 
The second one, the same supplier measured 100.1 $\mathrm{m}^{3} \pm 0.3 \mathrm{~m}^{3}(\mathrm{k}=2$; confidence level of 95.45) and the other consumer measured $100.0 \mathrm{~m}^{3} \pm 1.0 \mathrm{~m}^{3}$ (k = 2; confidence level of 95.45). The supplier used a turbine fiscal oil metering station, but the consumer used a storage tank (Figure 2). Considering a risk of $5 \%$ for the consumer, is there compliance between the parties?



This item is conform to an effective Consumer's Risk of $5 \%$.
Finally, one could notice that the use of guard bands based on measurement uncertainty is an interesting tool in compliance assessment in custody transfer operations. Moreover, the compliance assessment based on same measurement results between supplier and customers depends on the measuring systems (different measurement uncertainties) used and not only the transferred volume.

\section{References}

1. Williams A, Magnusson B (2021) Eurachem/CITAC Guide: Use of uncertainty information in compliance assessment. 2nd(Edn.), Eurachem.

2. Oliveira EC, Lourenço FR (2021) Risk of false conformity assessment applied to automotive fuel analysis: A multiparameter approach. Chemosphere 263: 128265.

3. Oliveira EC, Lourenço FR (2021) Data reconciliation applied to the conformity assessment of fuel products. Fuel 300: 120936.

4. OIML R 117-1, Edition 2007 (E), Dynamic measuring systems for liquids other than water. Part 1: Metrological and technical requirements, OIML.

5. Olivera EC, Queiroz CWT (2005) Metrological compatibility between dynamic and static measurement of oil, its liquid derivatives and alcohol. Rio Pipeline Conference \& Exposition. 